\title{
Simultaneous Kinetic Characterization of Multiple Protein Forms by Top Down Mass Spectrometry
}

\author{
Huili Zhai, Pieter C. Dorrestein, Abhishek Chatterjee, Tadhg P. Begley, \\ and Fred W. McLafferty \\ Department of Chemistry and Chemical Biology, Baker Laboratory, Cornell University, Ithaca, New York, \\ USA
}

Top down mass spectrometry, using a Fourier transform instrument, has unique capabilities for biomolecule kinetic studies, in that the concentration of large molecules in a reaction mixture can be monitored simultaneously from its mass spectrum produced by electrospray ionization. This is demonstrated with enzyme modifications occurring in the biosynthesis of the thiazole moiety of thiamin phosphate. The formation rate of ThiS-thiocarboxylate from ThiS was determined from the relative abundance of the corresponding $\mathrm{m} / \mathrm{z} 10162$ and 10146 isotopic peak clusters for all the observable charge states in the mass spectra measured at different reaction times. Even without measuring standard ionization efficiencies, the rate and precision of $0.018 \pm 0.004 \mathrm{~min}^{-1}$ agree well with the $0.027 \pm 0.003 \mathrm{~min}^{-1}$ obtained with a radiochemical assay, which requires a separate derivatization step. To illustrate the simultaneous characterization of the reaction kinetics of a native enzyme and its mutant, the imine formation rate of ThiG and its substrate DXP was compared between the native protein $\left(M_{r}=26803.9\right)$ and its E98A $\left(M_{r}=26745.9\right)$ or D182A $\left(M_{r}\right.$ $=26759.9$ ) mutant in the same reaction mixture. The kinetic data show clearly that neither the E98 nor the D182 residues participate in the imine formation. The high resolution and MS/MS capabilities of FTMS should make possible the extension of this kinetics approach to far more complicated systems, such as simultaneous monitoring of 24 native, intermediate, and reduced forms in the reductive unfolding of a mixture of ribonuclease $\mathrm{A}$ and the five isoforms of ribonuclease B. Stable intermediates with different $S-S$ bonding (same molecular weight) can be differentiated by MS/MS, while molecular ions differing by only $2 \mathrm{Da}$ are distinguished clearly by synthesizing isotopically depleted proteins. (J Am Soc Mass Spectrom 2005, 16, 1052-1059) (C) 2005 American Society for Mass Spectrometry

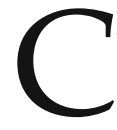
hemical transformations of proteins are basic to the function of all biological systems. A kinetic study deeper understanding of a biological mechanism. For example, characterization of the specific effect of a single enzyme mutation can require quantitative determination as a function of time of the mixed native and mutant enzymes and their modifications. The recent proteomics revolution has brought the development of powerful new techniques for characterizing the sequence and posttranslational modifications of individual proteins that are isolated from biological systems. The advantages of mass spectrometry (MS) for kinetic studies of small molecules are well known [1-4], but the application of MS to larger biomolecule kinetics has been limited to a single modification of a single protein without isotopic resolution $[5,6]$.

Published online May 23, 2005

Address correspondence to Dr. F. W. McLafferty, Department of Chemistry and Chemical Biology, Baker Laboratory, Cornell University, Ithaca, NY 14853-1301, USA. E-mail: fwm5@cornell.edu
Here we describe how "top down" tandem MS using a Fourier transform (FT) [7, 8] instrument can be applied to important kinetics problems involving multiple protein measurements, including direct activity comparison of multiple enzymes in the same solution.

Classical methods for kinetic monitoring of enzymatic product formation, such as use of a characteristic fluorescence wavelength, must be specific for the monitored chemical modification; multiple modifications require multiple probes. Often this necessitates derivatization of the protein with an appropriate chromophore, which adds concern for its influence on the reaction studied as well as complexity to the analysis. Measuring the kinetic behavior of a wild-type protein and its mutant, or of a number of protein isoforms, together in the same reaction mixture provides the most accurate comparison, but is seldom attempted because this multiplies the number of probes required.

In the top down MS approach $[9,10]$ to protein characterization, electrospray ionization (ESI) of a protein mixture yields a mass spectrum of protein molecular ions. 
FTMS is the favored instrumentation, as its high resolving power and mass accuracy can derive accurate $( \pm 1 \mathrm{Da})$ molecular weight values $\left(\mathrm{M}_{\mathrm{r}}\right)$ for more than 10 proteins from such a spectrum [11, 12]. Even a simple chemical modification such as methylation will make an easily distinguishable change $(+14 \mathrm{Da})$ in the $\mathrm{M}_{\mathrm{r}}$ value. Isomeric proteins (identical $\mathrm{M}_{\mathrm{r}}$ values), such as those methylated at different sites, can often be distinguished by MS/MS dissociation of their molecular ions [12].

Of course it is only when conventional techniques are inadequate that this expensive FTMS technique should be considered. Here we show that its $M_{r}$ values can conveniently provide definitive and semi-quantitative data for kinetic studies in protein mixtures. Using more rigorous MS techniques, it is generally possible to obtain far more accurate quantitation and sensitivity [13], but these were not necessary for the studies described here. For example, $\mathrm{M}_{\mathrm{r}}$ values provide highly specific probes for protein intermediates in the biosynthesis of the thiazole moiety of thiamin phosphate. Resolved $\mathrm{M}_{\mathrm{r}}$ values ( $\left.\sim 14 \mathrm{kDa}\right)$ and MS/MS also make possible the simultaneous monitoring of 24 native, intermediate, and reduced forms in the reductive unfolding of the six isoforms of ribonuclease A and B [14]. Possible top down MS kinetic studies in other important biological systems are discussed.

\section{Experimental}

\section{Overexpression of Proteins}

E. coli BL21(DE3) containing each plasmid was grown in LB media with ampicillin (50 $\mu \mathrm{g} / \mathrm{ml}$ media) shaking at $37^{\circ} \mathrm{C}$ until its $\mathrm{OD}_{600}$ reached 0.8 , at which point isopropyl$\beta$-D-thiogalactopyranoside (IPTG) was added to the culture to a final concentration of $500 \mu \mathrm{M}$, and growth was continued for another $8 \mathrm{~h}$ at $37^{\circ} \mathrm{C}$. For the copurification of ThiSG and ThiF, cultures containing pCLK820 and pCLK431 were prepared in 1000 and $500 \mathrm{ml} \mathrm{LB}$ media, respectively, mixed and harvested together. Cultures for B. subtilis YrvO were prepared in 1L LB media.

\section{Purification of Proteins}

The cells prepared above were resuspended in $5 \mathrm{ml}$ of lysis buffer (10 mM imidazole, $300 \mathrm{mM} \mathrm{NaCl}, 50 \mathrm{mM}$ $\mathrm{NaH}_{2} \mathrm{PO}_{4}, \mathrm{pH}$ 8.0) and lysed by sonication (Heat Systems Ultrasonics model W-385 sonicator, now Misonix, Farmingdale, NY, 2s cycle, 50\% duty, $4 \mathrm{~min}$ ). All proteins used in this study were purified using Ni-NTA resin following the manufacturer's instructions (Qiagen, Valencia, CA). After elution, protein solutions were buffer exchanged using a PD-10 column (Amersham, Piscataway, NJ, 50 mM Tris- $\mathrm{HCl}$, pH 8.0).

\section{Kinetics for the Formation of ThiS-Thiocarboxylate}

$2 \mathrm{mM}$ cysteine, $4 \mathrm{mM}$ ATP, $10 \mathrm{mM} \mathrm{MgCl}_{2}$, and ThiSGF $(3600 \mu \mathrm{g})$ were preincubated for $10 \mathrm{~min}$ before adding
$150 \mu \mathrm{l}$ YrvO $(540 \mu \mathrm{g})$ in $200 \mathrm{mM}$ Tris- $\mathrm{HCl} \mathrm{pH} 7.8$ (total volume $900 \mu \mathrm{l})$. Aliquots of the reaction mixture $(90 \mu \mathrm{l})$ were quenched at different time points by desalting via reverse-phase protein traps (Michrom Bioresources, Auburn, CA), washed with 1:98:1 (MeOH: $\left.\mathrm{H}_{2} \mathrm{O}: \mathrm{AcOH}\right)$, and eluted with 70:26:4 (MeOH: $\left.\mathrm{H}_{2} \mathrm{O}: \mathrm{AcOH}\right)$.

Samples representing $\sim 0.1 \mu \mathrm{g}$ of ThiSGF were analyzed by ESI-FTMS. The resulting intensities of ThiSthiocarboxylate were imported into sigmaplot and fitted to an exponential function.

\section{Kinetics on the Effect of Mutation on Imine Formation with ThiG}

A typical experiment was carried out by overexpressing ThiSG, ThiSG(E98A) and ThiSG(D182A) as separate cultures. The ThiSG culture (1L) was then harvested (by centrifugation) together with $1 \mathrm{~L}$ of ThiSG (E98A) or ThiSG (D182A) and stored at $-20{ }^{\circ} \mathrm{C}$ until use. The proteins were then purified and incubated with 1-deoxy-D-xylulose-5-phosphate (DXP) (500 $\mu \mathrm{M})$ to give a total volume of $512 \mu \mathrm{l}$ of $25 \mathrm{mM}$ Tris- $\mathrm{HCl}$, pH 7.7 containing thiazole synthase (5 $\mathrm{mg} / \mathrm{ml}$, as ThiSG) and mutants. The reaction mixture was then reduced by treatment with $\mathrm{NaBH}_{4}(200 \mathrm{mM})$ at various time points. The foam generated during the reduction was spun down in a clinical centrifuge for $2 \mathrm{~min}$ and $90 \mu \mathrm{l}$ of this solution was gel filtered using biospin columns (BIO-RAD Tris, Hercules, CA $\mathrm{pH} 7.4,0.02 \% \mathrm{NaN}_{3}$ ) to remove excess substrate and boron salts. The resulting protein solution was frozen and stored at $-80^{\circ} \mathrm{C}$ until it could be analyzed by ESI-FTMS. The resulting normalized intensities of molecular ions of the ThiG and ThiG +200 Da were plotted against time in sigmaplot and fitted with an exponential function. The molecular ions for ThiSG (E98A) and ThiG (E98A)+200 Da as well as ThiG (D182A) and ThiG (D182A)+200 Da were plotted in a similar fashion.

\section{Mass Spectrometric Analysis}

Protein samples were desalted by reverse-phase protein traps (Michrom Bioresources, Auburn, CA), washed with 1:98:1 (MeOH: $\left.\mathrm{H}_{2} \mathrm{O}: \mathrm{AcOH}\right)$, and eluted with 70: 26:4 (MeOH: $\left.\mathrm{H}_{2} \mathrm{O}: \mathrm{AcOH}\right)$. Solutions were electrosprayed at $1-50 \mathrm{nl} / \mathrm{min}$ with a nanospray emitter. The resulting ions were guided through a heated capillary, skimmer, and three radio frequency-only quadrupoles into a 6 T modified FTMS (ThermoFinnigan, San Jose, CA) ${ }^{\text {with }}$ the Odyssey ${ }^{\circ}$ data $^{\circ}$ system 915$]$. The' normalized peak intensities for different ion signals were obtained with ${ }^{\circ}$ computer $^{\circ}$ program $^{\circ} \mathrm{THRASH}^{\circ}[16]^{\circ} .^{\circ} \mathrm{The}^{\circ}$ mass $^{\circ}$ difference (in units of $1.00235 \mathrm{Da}$ ) between the most abundant isotopic peak and the monoisotopic peak is denoted in italics after each $M_{r}$ value. 


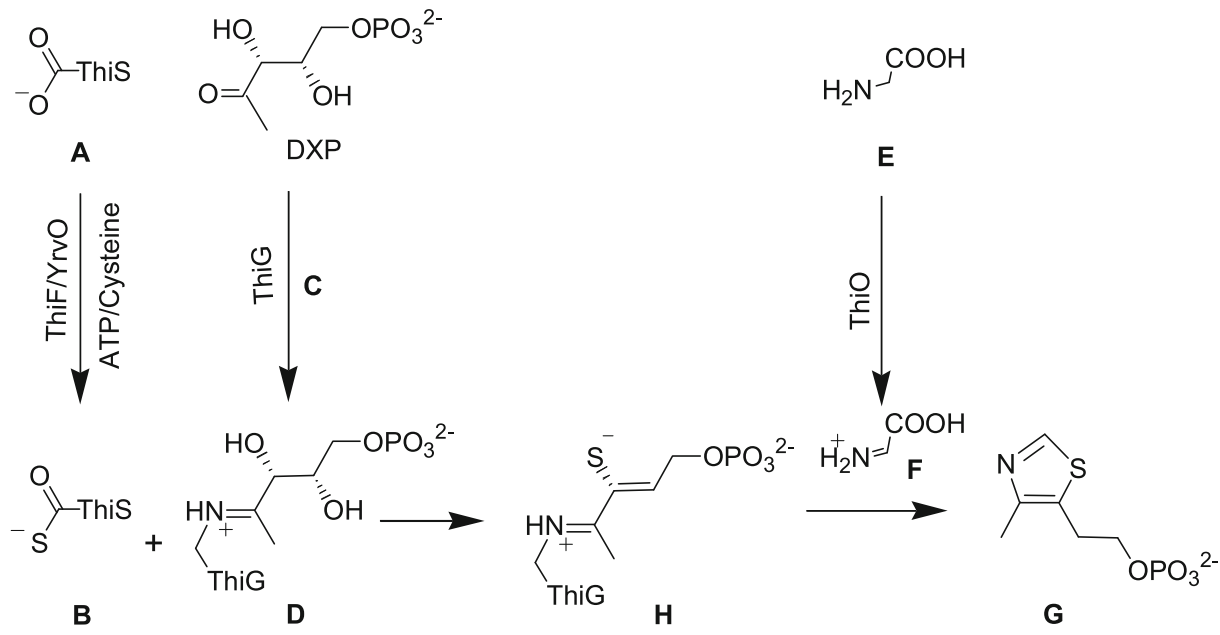

Figure 1. Biosynthesis of thiazole phosphate in B. subtilis.

\section{Results and Discussion}

Thiamin phosphate is an essential redox cofactor in all living systems where it functions to stabilize the acyl

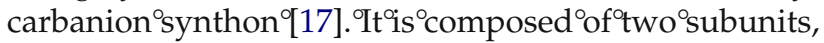
the pyrimidine moiety and the thiazole moiety. Recently, the biosynthesis of its thiazole moiety was successfully ${ }^{\circ}$ reconstituted ${ }^{\circ}{ }^{\circ} B$. subtilis [18] ${ }^{\circ}$ from $^{\circ}$ glycine (E), cysteine, and deoxy-D-xylulose-5-phosphate (DXP) using enzymes ThiS (A), YrvO, ThiF, ThiG (C), and ThiO. ${ }^{\circ} \mathrm{As}^{\circ}$ shown $^{\circ}$ in $^{\circ}$ Figure $^{\circ} 1{ }^{\circ}$ thiazole ${ }^{\circ}$ phosphate $^{\circ}(\mathbf{G})$ is formed by a reaction of the sulfur carrier protein ThiS-thiocarboxylate (B), ThiG-DXP imine (D) and dehydroglycine (F). The formation of ThiS-thiocarboxylate from ThiS was achieved by incubating ThiS carboxylate with YrvO, cysteine, ThiF, and ATP; while the oxidation of glycine to dehydroglycine was catalyzed by ThiO. In this paper, top down mass spectrometry is used to monitor the rate of the formation of ThiS thiocarboxylate and the effect of two ThiG mutations on the rate of reaction of ThiG and DXP.

\section{Kinetics of ThiS-Thiocarboxylate Formation}

ThiS-carboxylate (A) was incubated with ATP, cysteine, YrvO, ThiF, and ThiG (copurifies with $\mathbf{A}$ ) at room temperature. Samples were taken at designated time intervals ${ }^{\circ}$ (Figure $2 a$ ), ${ }^{\circ}$ the ${ }^{\circ}$ reaction ${ }^{\circ}$ quenched ${ }^{\circ}{ }^{\circ}{ }^{\circ}$ 'reverse phase desalting column, and the ESI spectrum measured. The normalized abundance for all the observable charge states of ThiS thiocarboxylate $\left(\mathbf{B}, \mathrm{M}_{\mathrm{r}}=10162.4\right)$ and $\left(\mathbf{A}, \mathrm{M}_{\mathrm{r}}=10146.4\right)$ from the computer program TRASH were summed, plotted, and fit to a single exponential function, giving a rate of $0.018 \pm 0.004$ $\min ^{-1^{\circ}}$ (Figure ${ }^{\circ} 2 \mathrm{~b}$ )..$^{\circ}$ Radiochemical ${ }^{\circ}$ assay $^{\circ}$ gave $^{\circ} 0.027^{\circ} \pm$ $0.003 \mathrm{~min}^{-1}$, so that the precision of the methods is comparable ${ }^{\circ}[18] .{ }^{\circ}$ This $^{\circ}$ small $^{\circ}$ difference ${ }^{\circ}{ }^{\circ}{ }^{\circ}$ rate $^{\circ}$ constants could arise from differences in experimental parameters (e.g., "room temperature", with months between experiments), but probably not from the difference in ESI ionization efficiency caused by substituting $-\mathrm{SH}$ for $-\mathrm{OH}$ in the $10 \mathrm{kDa}$ protein (although this was not measured).

Following the formation of ThiS-thiocarboxylate, the addition of DXP causes conversion of ThiS-thiocarboxylate ${ }^{\circ}$ back $^{\circ}$ to $^{\circ}$ ThiS-carboxylate $^{\circ}\left(\text { Figure }^{\circ} 3\right)^{\circ}{ }^{\circ} t^{\circ} a^{\circ}$ rate $^{\circ}(0.20$ $\pm 0.01 \mathrm{~min}^{-1}$ ) ten times faster than that of the ThiSthiocarboxylate $\mathbf{B}$ formation. This suggests that the role of $\mathbf{B}$ is the facile donation of sulfur to the ThiG-DXP imine ${ }^{\circ} \mathbf{D}$ (Figure $\left.{ }^{\circ} 1\right)^{\circ}$ to $^{\circ}$ yield $^{\circ}$ the ${ }^{\circ}$ key $^{\circ}$ intermediate ${ }^{\circ} \mathbf{H}$.

\section{Kinetics of Imine Formation by ThiG and its Mutants}

ThiG (C), the thiazole-phosphate synthase, forms an imine $^{\circ}(\mathrm{D})^{\circ}$ with $^{\circ}$ its $^{\circ}$ substrate $^{\circ} \mathrm{DXP}^{\circ}\left(\right.$ Figure $^{\circ} 1{ }^{\circ} \mathrm{M}_{\mathrm{r}}=$ 26803.9). This imine has been localized to the $-\mathrm{NH}_{2}$ group of $\mathrm{K} 96$ of the ThiG by top down mass spectrometry $^{\circ}$ analysis ${ }^{\circ}[19]^{\circ}{ }^{\circ} \mathrm{K} 6^{\circ}$ is ${ }^{\circ}$ found ${ }^{\circ}$ to $^{\circ}$ be $^{\circ}$ absolutely ${ }^{\circ}$ conserved by sequence alignment with other thiazole biosynthetic genes from phylogenetically diverse microorganisms. Mutation of K96 to an alanine resulted in a thiazole synthase $\left(M_{r}=26746.9\right)$ that cannot form either the ${ }^{\circ}$ imine ${ }^{\circ} \mathbf{D}$ or ${ }^{\circ}$ thiazole ${ }^{\circ}$ phosphate ${ }^{\circ} \mathbf{G}$ [20]..$^{\circ}$ Two $^{\circ}$ additional residues E98A and D182 are also absolutely conserved; E98 mutant of C showed a 38-fold decrease in the rate of formation of thiazole phosphate $\mathbf{G}$ and the D182A mutant was unable to form thiazole phosphate

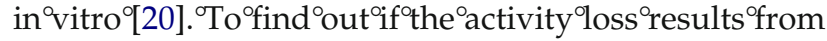
the direct involvement of these residues in imine $\mathbf{D}$ formation, or in the conversion of the imine $\mathbf{D}$ to the thiazole $\mathbf{G}$, the corresponding kinetic data were measured for both these mutants.

When DXP was added to a 1:1 mixture of ThiG and the D182A ThiG mutant at room temperature, aliquots of sample were immediately reduced to irreversibly trap the DXP-protein-imine $\mathbf{D}$ at different time points. The relative amounts of these products from wild ThiG and $^{\circ}$ its $^{\circ} \mathrm{E}^{\circ} 8 \mathrm{~A}^{\circ}$ mutant $^{\circ}$ plotted $^{\circ}$ against $^{\circ}$ time $^{\circ}\left(\right.$ Figure $\left.^{\circ} 4\right)$, 
(a)
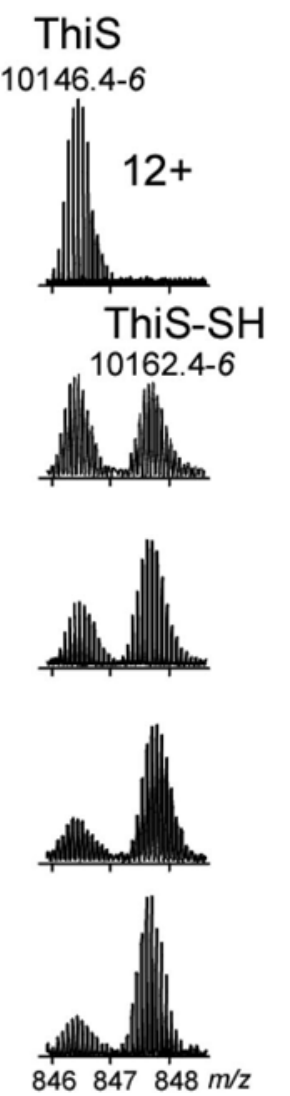

(b)

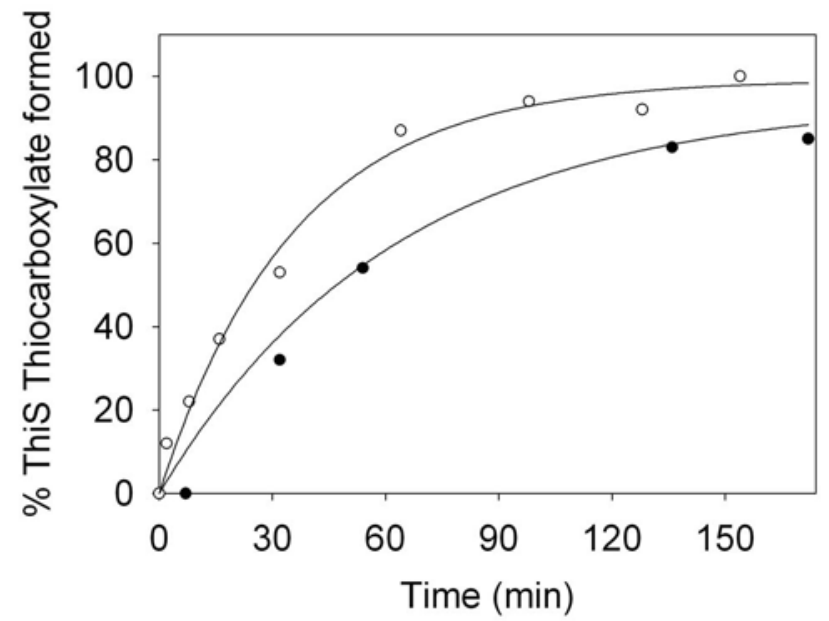

Figure 2. (a) ESI-FTMS spectra of the time dependent formation of ThiS thiocarboxylate. (b) Data from mass spectrometry (filled circles) and autoradiography (open circles).

both fit a first order function well, giving rates of imine formation of $2.6 \pm 0.1 \mathrm{~min}^{-1}$ and $3.1 \pm 0.1 \mathrm{~min}^{-1}$ respectively. When the same methodology was applied to a 1:1 mixture of ThiG and its E98A mutant to form the respective imine $\mathbf{D}$, the rates of $2.4 \pm 0.1 \mathrm{~min}^{-1}$ and $1.9^{\circ} \pm^{\circ} 0.1^{\circ} \mathrm{min}^{-1}{ }^{\circ}$, respectively $^{\circ}\left(\right.$ Figure $\left.^{\circ} 5\right)$, ${ }^{\circ}$ implied $^{\circ}$ that mutation lowered the efficiency slightly. However, these differences can hardly account for the great reduction observed in the rate for thiazole-phosphate $\mathbf{G}$ formation. Based on these kinetic data obtained under identical experimental conditions, the mutations at residues E98 and D182 have a far larger effect on $\mathbf{D}+\mathbf{F} \rightarrow$ G than on DXP + ThiG $\rightarrow$ D, in contrast to the K96 mutation that stopped $\mathbf{D}$ formation.

\section{Possible Extensions of Top Down MS Kinetic Studies}

From the ESI mass spectrum of a poly(ethene/propene) glycol copolymer exhibiting $130 \mathrm{M}_{\mathrm{r}}$ values, the sequences of five oligomer molecular ions of $\sim 1 \%$ relative abundance were successfully characterized by MS/MS [21]. Thus, ${ }^{\circ}$ top ${ }^{\circ}$ down ${ }^{\circ} \mathrm{MS}^{\circ}{ }^{\circ}{ }^{\circ} \mathrm{MS} / \mathrm{MS}^{\circ}$ kinetic $^{\circ}$ studies ${ }^{\circ}$ of far more complicated protein systems should be feasible. As a possible system, a recent top down MS study characterized the intermediates in the reductive unfold- ing of bovine pancreatic ribonuclease $\mathrm{A}$ (RNase A) and five isoforms of RNase B, each with a different, naturally ${ }^{\circ}$ occurring ${ }^{\circ}$ carbohydrate $^{\circ}$ moiety $^{\circ}[14] . .^{\circ}$ The $^{\circ}$ kinetic $^{2}$ parameters of the reductive unfolding measured by HPLC showed little difference between the A and B. However, HPLC could not separate the five isoforms of RNase B to determine the kinetics of each individual isoform. A kinetic study of the simultaneous unfolding of RNase A and B would require simultaneous detection of the six folded and six completely unfolded forms; five $M_{r}$ values of the latter are easily characterized $^{\circ}$ in $^{\circ}$ the ${ }^{\circ}$ ESI $/$ FTMS $^{\circ}$ spectrum ${ }^{\circ}$ of ${ }^{\circ}$ Figure $^{\circ} 6 .^{\circ}$ Stable intermediates with one $\mathrm{S}-\mathrm{S}$ bond cleaved were identified by derivatization of the new $-\mathrm{SH}$ groups that modified the $M_{r}$ values, while MS/MS differentiated the two stable isomers with a different $S-S$ bond reduced. Thus, such a simultaneous kinetic study of six protein isoforms, measuring for each its native, two intermediate, and reduced forms, a total of 24 compounds should be possible by top down ESI/FTMS.

Without $-\mathrm{SH}$ derivatization, disulfide bond formation only involves a $2 \mathrm{Da}$ mass decrease, so that the resulting isotope distribution pattern will overlap that of the native molecular ion, reducing the abundance accuracy for the determination of these compounds. Stable intermediates from further disulfide bond cleav- 
(a)

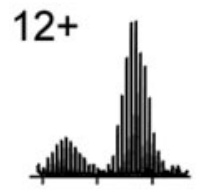

ThiS ThiS-SH
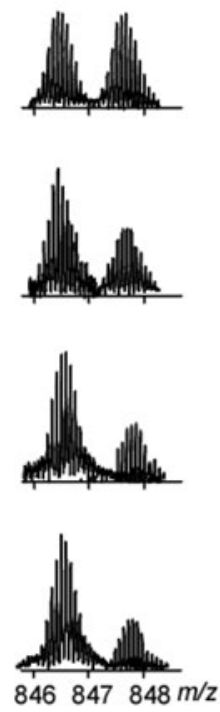

(b)

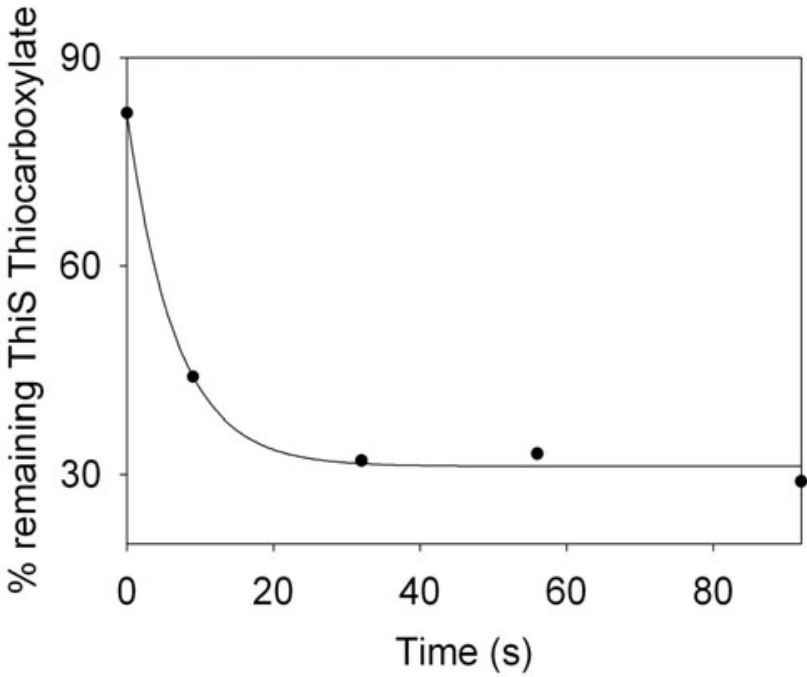

Figure 3. (a) ESI-FTMS spectra and (b) plot of the time dependent conversion from ThiS thiocarboxylate back to ThiS-carboxylate.

(a)

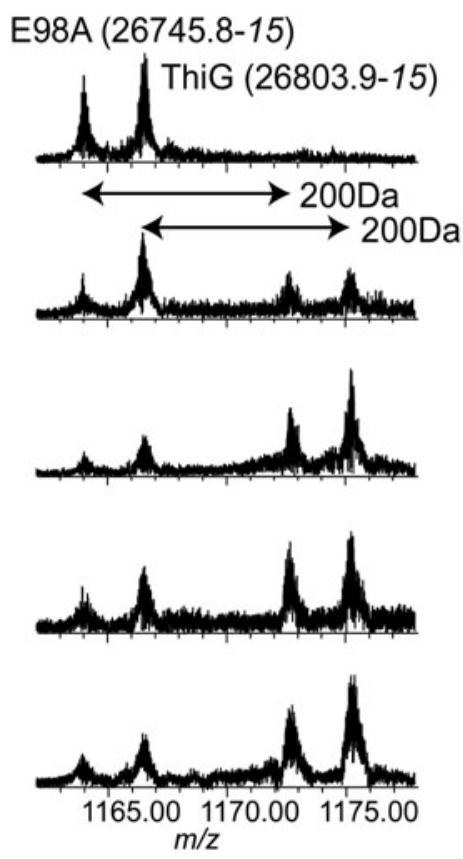

(b)

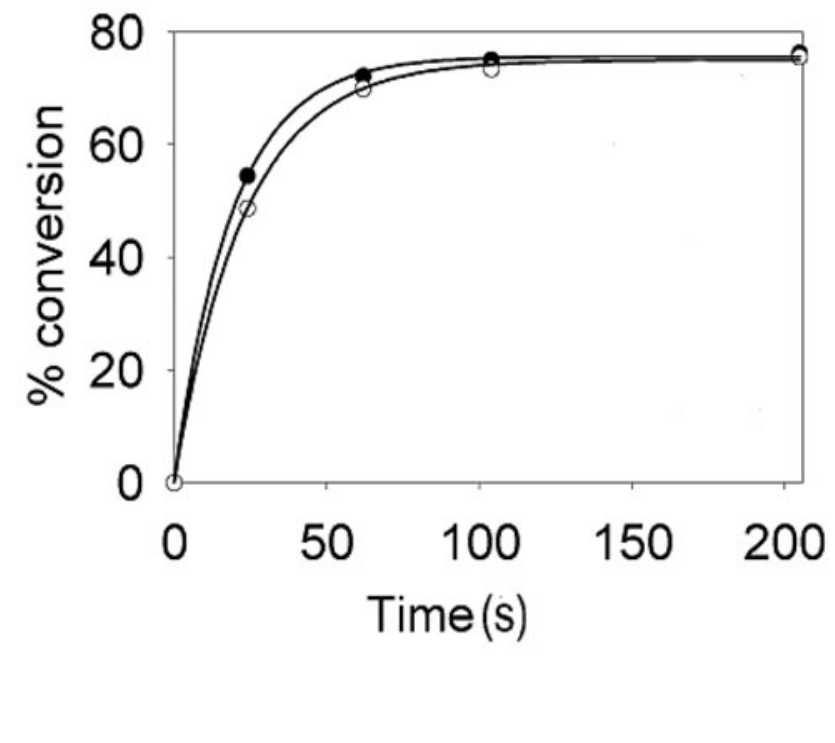

Figure 4. (a) ESI-FTMS spectra and (b) plots of the simultaneous time dependent formation of imine adduct $\mathbf{D}$ from wild type ThiG (open circles) and its E98A mutant (filled circles). 
(a)

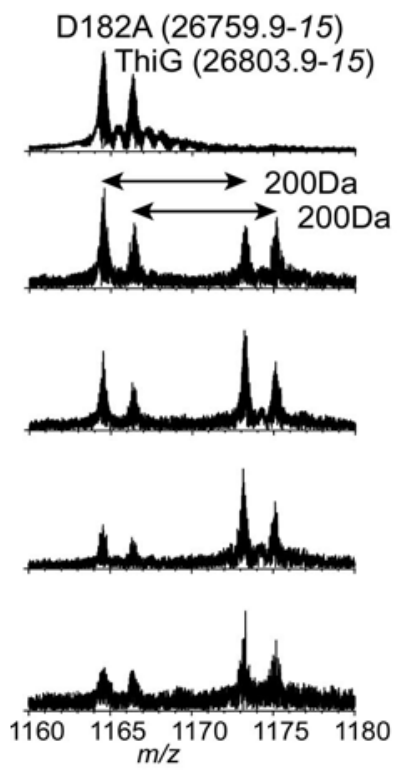

(b)

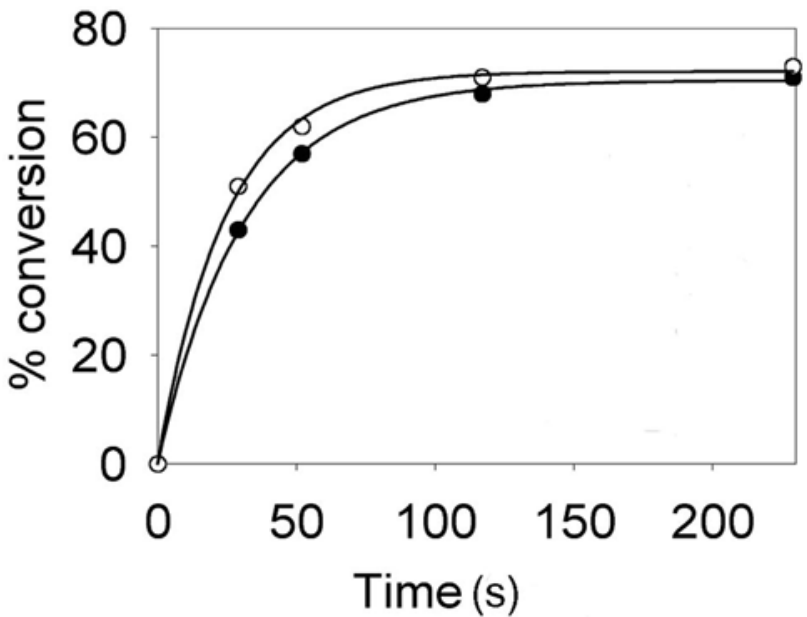

Figure 5. (a) ESI-FTMS spectra and (b) plots of the simultaneous time dependent formation of imine adduct D from wild type ThiG (open circles) and its D182A mutant (filled circles).

age would, in the same way, give molecular ions with isotopic peak distributions at lower mass. The complexity of the resulting isotopic peak distribution can be greatly reduced, as well as signal intensity improved, by preparing the sample with its heavy isotopes depleted ${ }^{\circ}[22] .{ }^{\circ}$ Figure $^{\circ} 7^{\circ}$ illustrates ${ }^{\circ}$ the $^{\circ}$ change $^{\circ}$ in ${ }^{\circ}$ isotopic distribution for ThiS grown from ${ }^{13} \mathrm{C}$ and ${ }^{15} \mathrm{~N}$ depleted media, in which the monoisotopic peak has become the most abundant of the molecular ions. This could provide relatively accurate determination of intermediates whose $\mathrm{M}_{\mathrm{r}}$ values ${ }^{\circ}$ differ ${ }^{\circ} \mathrm{by}^{\circ}$ only $^{\circ}{ }^{\circ} \mathrm{Da}^{\circ}[23]$.

Other possible systems amenable to this top down ESI-FTMS kinetic approach include phosphorylation and $^{\circ}$ acylations ${ }^{\circ}$ of $^{\circ}$ histones $^{\circ}[24]$, thioester $^{\circ}$ formation $^{\circ}$ of polyketide and non-ribosomal peptide biosynthetic sys- tems ${ }^{\circ}\left[25,{ }^{\circ} 26\right],{ }^{\circ}$ disulfide ${ }^{\circ}$ bond ${ }^{\circ}$ formation ${ }^{\circ}$ during ${ }^{\circ}$ protein folding ${ }^{\circ}[27]$, and $^{\circ}$ adenylation $^{\circ}$ and $^{\circ}$ sulfurylation $^{\circ}$ of ${ }^{\circ}$ the sulfur carrier proteins such as the ones found in thiazole-phosphate ${ }^{\circ}$ biosynthesis $^{\circ}$ [28]. ${ }^{\circ}$ McLoughlin ${ }^{\circ}$ and Kelleher have just recently done a similar FTMS kinetic study that simultaneously follows seven covalent modifications to the PCP1 active site peptide Val ${ }^{1396}-\mathrm{Met}^{1580}$ $\left(\mathrm{M}_{\mathrm{r}}=20705\right)$ from apo-HMWP2 of Yersiniabactin biosynthesis ${ }^{\circ}[29]$.

\section{Conclusions}

Top down ESI/FTMS has been able to compare directly, under identical experimental conditions, the reaction kinetics of a native enzyme and its mutants. Further, the

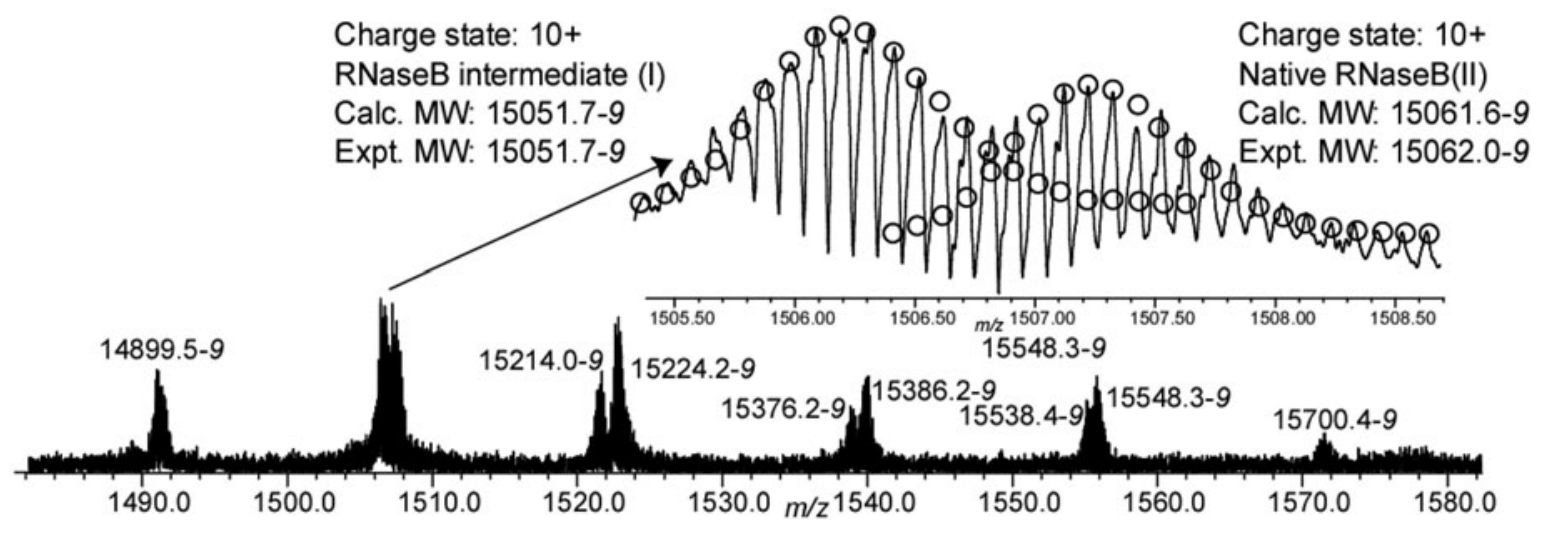

Figure 6. Partial ESI/FTMS spectra of the reductive unfolding mixture of RNase B, showing the overlapping peaks of the five isoforms (differing in the number of mannose molecule, $\Delta \mathrm{M}_{\mathrm{r}}=162.2$ ) of totally reduced RNase B and their three-disulfide-containing reductive intermediates. Dots on the expanded portions represent the theoretical abundance distribution of the isotopic peaks. 

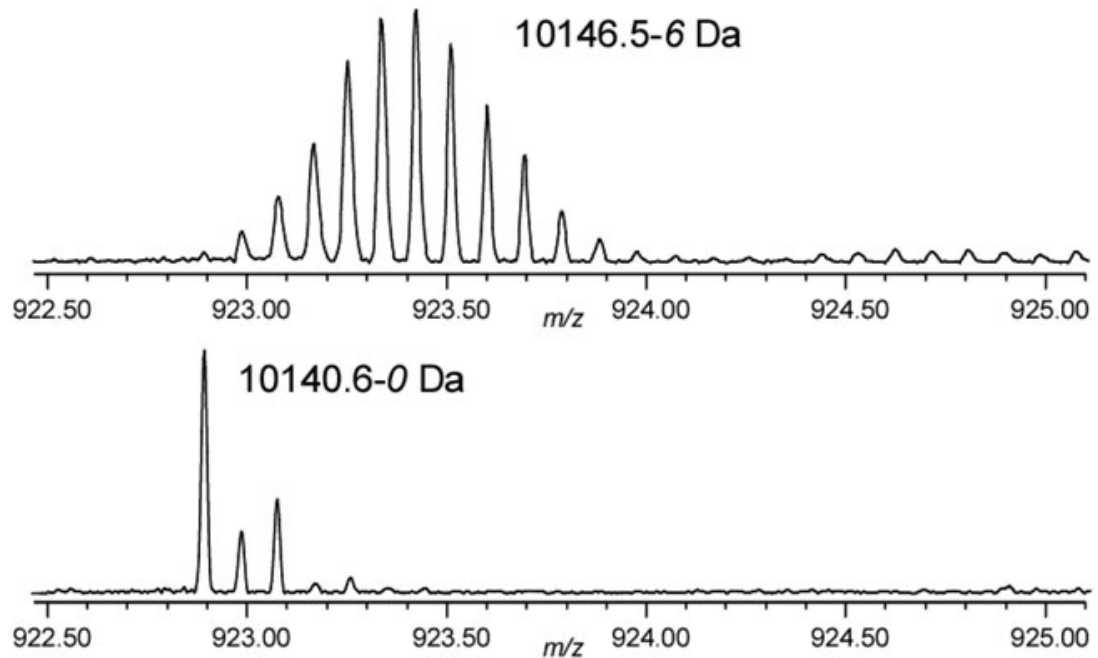

Figure 7. ESI/FTMS spectra of (a) normal ThiS protein and (b) ThiS grown in ${ }^{13} \mathrm{C}$ and ${ }^{15} \mathrm{~N}$ depleted media.

isotopic resolution and MS/MS capabilities demonstrate a potential for ready extension to other systems of far greater complexity. The chief limitation of conventional methods for kinetic studies of proteins and other large biological molecules is the lack of highly specific probes that do not affect reactivity. With MS, the thousands of possible $\mathrm{M}_{\mathrm{r}}$ values can serve as just such probes. Mutants or isoforms of an enzyme, and their reaction products, will give different $\mathrm{M}_{\mathrm{r}}$ values. Small differences (e.g., $2 \mathrm{Da}$ ) in $\mathrm{M}_{\mathrm{r}}$ values give lower accuracy because of overlapping isotopic distributions, but biosynthesis of the protein with depleted heavy isotopes alleviates this problem. Even constituents with the same $M_{r}$ value, such as the derivatized RNase with two different $\mathrm{S}-\mathrm{S}$ bonds reduced, can be monitored separately by MS/MS. Mutants and reaction products often have similar ionization efficiencies, making standardization unnecessary for relative comparisons. This capability to measure directly the kinetics of individual protein reactions in complex mixtures should find many valuable applications in biomedical research and drug development.

\section{Acknowledgments}

The authors gratefully acknowledge Harold Scheraga, Guoqiang $\mathrm{Xu}$, Mahesh Narayan, Kathrin Breuker, Cheng Lin, Xuemei Han, and Harold Huang for valuable discussions, and the National Institutes of Health (grant GM16609 to FWM and grant DK44083 to TPB) for generous funding.

The authors dedicate this study of protein kinetics in honor of Michael Bowers. His highly deserved ASMS Distinguished Contribution Award is for "his fundamental contribution to ionneutral collision theory." Although the high level of physical chemistry and theory that made this landmark achievement possible can only be fully appreciated by true experts in that specialty, it has benefited all of us in mass spectrometry by providing a far more solid mechanistic foundation for our field.

\section{References}

1. Hsieh, F. Y. L.; Tong, X.; Wachs, T.; Ganem, B.; Henion, J. Kinetic Monitoring of Enzymatic Reactions in Real Time by Quantitative High-Performance Liquid ChromatographyMass Spectrometry. Anal. Biochem. 1995, 229, $20-25$.

2. Bothner, B.; Chavez, R.; Wei, J.; Strupp, C.; Phung, Q.; Schneemann, A.; Siuzdak, G. Monitoring Enzyme Catalysis with Mass Spectrometry. J. Biol. Chem. 2000, 275, 13455-13459.

3. Ge, X.; Sirich, T. L.; Beyer, M. K.; Desaire, H.; Leary, J. A. A Strategy for Determination of Enzyme Kinetics Using Electrospray Ionization with an Ion Trap Mass Spectrometer. Anal. Chem. 2001, 73, 5078-5082, and references cited therein.

4. Gerber, S. A.; Scott, C. R.; Turecek, F.; Gelb, M. H. Direct Profiling of Multiple Enzyme Activities in Human Cell Lysates by Affinity Chromatography/Electrospray Ionization Mass Spectrometry: Application to Clinical Enzymology. Anal. Chem. 2001, 73, 1651-1657.

5. Zechel, D. L.; Konermann, L.; Withers, S. G.; Douglas, D. J. Pre-steady State Kinetic Analysis of an Enzymatic Reaction Monitored by Time-Resolved Electrospray Ionization Mass Spectrometry. Biochemistry 1998, 37, 7664-7669.

6. Houston, C. T.; Taylor, W. P.; Widlanski, T. S.; Reilly, J. P. Investigation of Enzyme Kinetics Using Quench-Flow Techniques with MALDI-TOF Mass Spectrometry. Anal. Chem. 2000, 72, 3311-3319.

7. Comisarow, M. B.; Marshall, A. G. Fourier Transform Ion Cyclotron Resonance Spectroscopy. Chem. Phys. Lett. 1974, 25, 282-283.

8. Amster, I. J. Fourier Transform Mass Spectrometry. J. Mass Spectrom. 1996, 31, 1325-1337.

9. Kelleher, N. L.; Lin, H. Y.; Valaskovic, G. A.; Aaserud, D. J.; Fridriksson, E. K.; McLafferty, F. W. Top Down Versus Bottom Up Protein Characterization by Tandem High-Resolution Mass Spectrometry. J. Am. Chem. Soc. 1999, 121, 806-812.

10. Ge, Y.; Lawhorn, B. G.; ElNaggar, M.; Strauss, E.; Park, J.; Begley, T. P.; McLafferty, F. W. Top Down Characterization of Larger Proteins $(45 \mathrm{kDa})$ by Electron Capture Dissociation Mass Spectrometry. J. Am. Chem. Soc. 2002, 124, 672-678.

11. Ge, Y.; ElNaggar, M.; Sze, S. K.; Oh, H.; Begley, T. P.; McLafferty, F. W.; Boshoff, H.; Barry, C. E. Top Down Characterization of Secreted Proteins from Mycobacterium tubercu- 
losis by Electron Capture Dissociation Mass Spectrometry. J. Am. Soc. Mass Spectrum. 2003, 14, 253-261.

12. Zabrouskov, V.; Giacomelli, L.; van Wijk, K. J.; McLafferty, F. W. A New Approach for Plant Proteomics: Characterization of Chloroplast Proteins of Arabidopsis thaliana by Top Down Mass Spectrometry. Mol. Cell. Proteom. 2003, 2, 1253-1260.

13. Valaskovic, G. A.; Kelleher, N. L.; McLafferty, F. W. Attomole Protein Characterization by Capillary Electrophoresis/Mass Spectrometry. Science 1996, 273, 1199-1202.

14. Xu, G.; Zhai, H.; Narayan, M.; McLafferty, F. W.; Scheraga, H. A. Simultaneous Characterization of the Reductive Unfolding Pathways of RNase B Isoforms by Top Down Mass Spectrometry. Chem. Biol. 2004, 11, 517-524.

15. Beu, S. C.; Senko, M. W.; Quinn, J. P.; Wampler, F. M.; McLafferty, F. W. Fourier-Transform Electrospray Instrumentation for Tandem High-resolution Mass Spectrometry of Large Molecules. J. Am. Soc. Mass Spectrom. 1993, 4, 557-565.

16. Horn, D. M.; Zubarev, R. A.; McLafferty, F. W. Automated Reduction and Interpretation of High Resolution Electrospray Mass Spectra of Large Molecules. J. Am. Soc. Mass. Spectrom. 2000, 11, 320-332.

17. Jordan, F. Current Mechanistic Understanding of Thiamin Diphosphate-Dependant Enzymatic Reactions. Nat. Prod. Rep. 2003, 20, 184-201.

18. Park J.; Dorrestein, P. C.; Zhai, H.; Kinsland, C.; McLafferty, F. W.; Begley, T. P. Biosynthesis of the Thiazole Moiety of Thiamin Pyrophosphate (Vitamin B1). Biochemistry 2003, 42, 12430-12438.

19. Dorrestein, P. C.; Zhai, H.; Taylor, S. V.; McLafferty, F. W.; Begley, T. P. The Biosynthesis of the Thiazole Phosphate Moiety of Thiamin (Vitamin $B_{1}$ ): The Early Steps Catalyzed by Thiazole Synthase. J. Am. Chem. Soc. 2004, 126, 3091-3096.

20. Settembre, E. C.; Dorrestein, P. C.; Zhai, H.; Chatterjee, A.; McLafferty, F. W.; Begley, T. P.; Ealick, S. E. Thiamin Biosynthesis in Bacillus subtilis: Structure of the Thiazole Synthase/ Sulfur Carrier Protein Complex. Biochemstry 2004, 43, 1164711657.
21. Cerda, B. A.; Horn, D. M.; Breuker, K.; McLafferty, F. W. Sequencing of Specific Copolymer Oligomers by ElectronCapture-Dissociation Mass Spectrometry. J. Am. Chem. Soc. 2002, 124, 9287-9291.

22. Marshall, A. G.; Senko, M. W.; Li, W.; Li, M.; Dillon, S.; Guan, S.; Logan, T. M. Protein Molecular Weight to 1 Da by 13C, 15N Double-Depletion and FT-ICR Mass Spectrometry. J. Am. Chem. Soc. 1997, 119, 433-434.

23. Dorrestein, P. C.; Zhai, H.; McLafferty, F. W.; Begley, T. P. The Biosynthesis of the Thiazole Phosphate Moiety of Thiamin: The Sulfur Transfer Mediated by the Sulfur Carrier Protein ThiS. Chem. Biol. 2004, 11, 1373-1381.

24. Pesavento, J. J.; Kim, Y.; Taylor, G. K.; Kelleher, N. L. Shotgun Annotation of Histone Modifications: A New Approach for Streamlined Characterization of Proteins by Top Down Mass Spectrometry. J. Am. Chem. Soc. 2004, 126, 3386-3387.

25. Hicks, L. M.; O'Conner, S. E.; Mazur, M. T.; Walsh, C. T.; Kelleher, N. L. Mass Spectrometric Interrogation of ThioesterBound Intermediates in the Initial Stages of Epothilone Biosynthesis. Chem. Biol. 2004, 11, 327-335.

26. Mazur, M. T.; Walsh, C. T.; Kelleher, N. L. Site-Specific Observation of Acyl Intermediate Processing in Thiotemplate Biosynthesis by Fourier Transform Mass Spectrometry. Biochemistry 2003, 42, 13393-13400.

27. Narayan, M.; Xu, G.; Ripoll, D.; Zhai, H.; Breuker, K.; Wanjalla, C.; Ceung, H. J.; Navon, A.; Welker, E.; McLafferty, F. W.; Scheraga, H. A. Dissimilarity in the Reductive Unfolding Pathways of Two Ribonuclease Homologues. J. Mol. Biol. 2004, 338, 795-809.

28. Xi, J.; Ge, Y.; Kinsland, C.; McLafferty, F. W.; Begley, T. P. Biosynthesis of the Thiazole Moiety of Thiamin in Escherichia coli: Identification of an Acyldisulfide-Linked Protein-Protein Conjugate that is Functionally Analogous to the Ubiquitin/E1 Complex. Proc. Natl. Acad. Sci. U.S.A. 2001, 98, 8513-8518.

29. McLoughlin, S. M.; Kelleher, N. L. Kinetic and Regiospecific Interrogation of Covalent Intermediates in the Biosynthesis of Yersiniabactin. J. Am. Chem. Soc. 2004, 126, 13265-13275. 